\title{
PENGARUH KOLOM KAPUR TERHADAP POTENSI MENGEMBANG DAN PENINGKATAN KEKUATAN TANAH EKSPANSIF DENGAN PENGALIRAN DARI TANAH KE KOLOM
}

\author{
Fabianus Danang Istanto 1), Bambang Setiawan 2), Noegroho Djarwanti 2) \\ 1) Mahasiswa Fakultas Teknik, Program Studi Teknik Sipil, Universitas Sebelas Maret \\ 2) Pengajar Fakultas Teknik, Program Studi Teknik Sipil, Universitas Sebelas Maret \\ Jl. Ir. Sutami 36A, Surakarta 5716; Telp. 0271-634524. Email : fabianusdanang20@gmail.com
}

\begin{abstract}
Expansive soil is easy to swell when the water content is high and easily shrinks when the water content is low. The swelling potential of expansive soil can cause problems, because it can cause the building uplifted so that demage pavement and buildings. Jenggrik Village, Kedunggalar Sub District, Ngawi, East Java is one of the areas that have black soil charasteristic and has high plasticity. Problems arising from expansive soils can be anticipated if an alternative repair is made.

This research uses soil improvement method with lime column. The research parameters were to know the effect of lime column on swelling potential, improvement of plasticity value, increase of unconfined compression test and lime spreading after 20 wetting days. The main test was performed in a drum with a diameter of $56 \mathrm{~cm}$ and a height of $43 \mathrm{~cm}$. High of expansive soil $30 \mathrm{~cm}$ and planted 7 columns of lime with diameter $(D)=5 \mathrm{~cm}$. Distance between columns $(\mathrm{L})=2.75 \mathrm{D}$ and depth of column $\left(D_{f}\right)=2 / 3$ thick. from the soil. The soil in dhe test drum is dampened daily though side drainage with a thickness of $5 \mathrm{~cm}$ and depth of $20 \mathrm{~cm}$.

The results showed that the use of lime columns could decrease the swelling potential of expansive soil by $4.84 \%$. The result of plasticity index (PI) after soil 20 days swelling decreased by 39.21\%. The unconfined compression strength ( $\left(q_{u}\right)$ comes from a test sample area I, II, III by $9.53 \%$ and $\left(S_{u}\right)$ by $10.36 \%$. The XRF test showed that Ca chemical result increased from $7.56 \%$ to $16.62 \%$.
\end{abstract}

Keywords : expansive, lime column, swelling, spreading.

\begin{abstract}
Abstrak
Tanah ekspansif memiliki sifat mudah mengembang ketika kadar air tinggi dan mudah susut ketika kadar air rendah. Potensi mengembang tanah ekspansif dapat menimbulkan masalah, karena dapat menyebabkan bangunan terangkat sehingga merusak perkerasan jalan dan bangunan. Desa Jenggrik, Kecamatan Kedunggalar, Ngawi, Jawa timur merupakan salah satu daerah yang memiliki karakteristik tanah berwarna hitam dan memiliki plastisitas tinggi. Permasalahan akibat tanah ekspansif dapat diantisipasi apabila dilakukan suatu alternatif perbaikan.

Penelitian ini menggunakan metode perbaikan tanah dengan kolom berisi kapur. Parameter penelitian adalah mengetahui pengaruh kolom kapur terhadap potensi mengembang, perbaikan nilai plastisitas, peningkatan kuat tekan bebas tanah dan penyebaran kapur setelah 20 hari pembasahan. Pengujian utama dilakukan dalam drum berdiameter $56 \mathrm{~cm}$ dan tinggi $43 \mathrm{~cm}$. Tinggi tanah ekspansif $30 \mathrm{~cm}$ ditanami 7 kolom kapur dengan diameter $(D)=5 \mathrm{~cm}$. Jarak antar kolom $(L)=2,75 D$ dan kedalaman kolom $\left(D_{f}\right)=$ $2 / 3$ tebal tanah. Tanah dalam drum uji dibasahi setiap hari melalui drainase samping dengan tebal $5 \mathrm{~cm}$ dan kedalaman $20 \mathrm{~cm}$.

Hasil penelitian menunjukkan penggunaan kolom kapur dapat menurunkan nilai potensi mengembang tanah ekspansif sebesar 4,84\%. Hasil indeks plastisitas (PI) setelah proses mengembang 20 hari menurun sebesar 39,21\%. Kenaikan kuat tekan bebas $\left(q_{u}\right)$ terbesar berasal dari sampel area I, II, III sebesar 9,53\% dan $\left(S_{u}\right)$ sebesar 10,36\%. Uji XRF menunjukkan hasil unsur kimia Ca mengalami kenaikan dari 7,56\% menjadi $16,62 \%$.
\end{abstract}

Kata kunci: ekspansif, kolom kapur, mengembang, penyebaran. 


\section{PENDAHULUAN}

Tanah merupakan bagian bumi yang sangat penting dalam kegiatan konstruksi sipil, karena sebagai pijakan yang menerima beban bangunan di atasnya. Bangunan sipil di Indonesia sering terjadi kegagalan karena jenis tanah yang buruk dan labil. Tanah ekspansif memiliki sifat mudah mengembang ketika kadar air tinggi dan mudah susut ketika kadar air rendah. Negara Indonesia yang memiliki dua musim yaitu kemarau dan penghujan, akan berpotensi besar mempengaruhi perubahan kadar air. Penelitian ini dilakukan pada tanah ekspansif yang ditanami kolom kapur serta melakukan pembasahan menuju kolom. Hasil penelitian berasal dari pengamatan pengaruh kolom kapur terhadap peristiwa mengembang (swelling) yang dibutuhkan untuk menjaga tanah agar tidak mengembang secara ekstrim, membandingkan hasil uji indeks properties setelah pembasahan dan mengetahui penyebaran kapur dalam tanah ditinjau dari perubahan volume kolom, hasil uji Unconfined compression strength (UCS) dan hasil uji X-Ray Flourescence (XRF).

\section{TINJAUAN PUSTAKA DAN LANDASAN TEORI}

\section{Tanah ekspansif}

Tanah ekspansif merupakan tanah yang mudah berubah volumenya karena adanya peristiwa kembang dan susut. Tanah mengalami perubahan volume karena mengandung senyawa bernama montmorillonite dengan potensi mengembang tinggi. Potensi tanah untuk menarik air tergantung pada kadar air awal, semakin kering kondisi kadar air maka potensi untuk menarik air bertambah besar, selain itu batas konsistensi tanah dapat mempengaruhi potensi tanah untuk mengembang.

\section{Tingkat ekspansifitas}

Identifikasi tanah ekspansif ditentukan dengan menggunakan nilai indeks plastisitas $(P I)$ dan indeks susut $(S I)$, derajat pengembangan sangat tinggi terjadi pada tanah dengan nilai $P I>32 \%$ dan $S I>60 \%$. Tanah yang memiliki derajat pengembangan tinggi selalu memiliki batas cair $(L L)>90 \%$.

\section{Metode kolom}

Pembuatan kolom merupakan suatu upaya untuk menstabilkan tanah labil. Metode ini dilakukan dengan membuat lubang terlebih dahulu pada tanah yang hendak distabilkan dan diisi bahan kimia kedalam lubang tersebut, bahan kimia yang dimaksud dapat berupa kapur, karbit, dan bahan kimia yang dapat digunakan untuk stabilisasi lainnya.

\section{Penggunaan kapur dalam stabilisasi kimiawi}

Penambahan kapur dalam stabilisasi tanah akan menghasilkan pengurangan sifat-sifat plastisitas dan potensi pengembangan, kepadatan atau berat volume kering tanah, dan kenaikan kapasitas dukung tanah adalah akibat dari beberapa hasil reaksi, yaitu :

1. Perubahan lapisan film air disekitar mineral tanah. Kekuatan ikatan antara dua mineral tanah bergantung pada muatan, ukuran, dan hidrasi dari ion-ion yang tertarik. Ion kalsium (kapur) adalah divalen dan mengikat partikel tanah. Pengaruh dari hal ini adalah mengurangi plastisitas.

2. Adanya flokulasi dari partikel-partikel tanah.

3. Reaksi kapur dengan komponen tanah yang membentuk bahan kimia baru.

\section{Uji tekan tak terkekang (Unconfined Compression Strength)}

Tegangan yang bekerja pada uji tekan bebas dinotasikan dengan $\sigma_{1}$ (tegangan utama mayor), $\sigma_{2}$ (tegangan utama tengah), $\sigma_{3}$ (tegangan utama minor). Tegangan utama tengah $\left(\sigma_{2}\right)$ sering tidak diperhitungkan karena uji UCS hanya ditinjau secara dua dimensi. Sampel tanah yang diletakkan secara vertikal akan terkena teganagan utama mayor $(\sigma 1)$ dari atas dan bawah, sedangkan tegangan utama minor $(\sigma 3)$ pada uji tekan bebas tidak ada kekangan $(\sigma 3=0)$.

\section{Uji $X$-Ray Fluorescence (XRF)}

Uji $X$-ray fluorescence $(X R F)$ dapat digunakan untuk menganalisis kandungan biologis maupun kandungan kandungan industri dengan menggunakan metode sinar-X. Pengujian mineral tanah dengan uji XRF sangat ramah lingkungan, karena analisis memiliki sifat tidak merusak (nondestruktif), cepat, dan multi elemen. Hasil uji mineral akan menunjukkan hasil montmorillonite pada tanah yang memiliki potensi mengembang tinggi tidak lebih dari 35 sampai 50\%. 
Lempung umumnya terdiri dari tiga mineral utama, antara lain :
1. Montmorillonite
$=\mathrm{Al}_{2} \mathrm{O}_{3} 4 \mathrm{SiO}_{2} \mathrm{H}_{2} \mathrm{O}$
2. $\quad$ Illite
$=\mathrm{H}_{2} \mathrm{KAI}_{3} \mathrm{O}_{12}$
3. Kaolinite
$=\left[\mathrm{Al}_{2}(\mathrm{OH})_{4}\left(\mathrm{Si}_{2} \mathrm{O}_{3}\right)\right]_{2}$

\section{METODE PENELITIAN}

Penelitian ini menggunakan metode perbaikan tanah dengan kolom berisi kapur. Pengujian utama dilakukan dalam drum berdiameter $56 \mathrm{~cm}$ dan tinggi $43 \mathrm{~cm}$. Tinggi tanah ekspansif $30 \mathrm{~cm}$ ditanami 7 kolom kapur dengan diameter $(\mathrm{D})=5 \mathrm{~cm}$. Jarak antar kolom $(L)=2,75 \mathrm{D}$ dan kedalaman $\operatorname{kolom}\left(D_{f}\right)=$ $2 / 3$ tebal tanah. Tanah dalam drum uji dibasahi setiap hari melalui drainase samping dengan tebal $5 \mathrm{~cm}$ dan kedalaman $20 \mathrm{~cm}$. Penamaan kolom kapur terdiri dari nomor 1-7.

Tujuan penelitian adalah mengetahui pengaruh kolom kapur terhadap potensi mengembang, perbaikan nilai plastisitas, peningkatan kuat tekan bebas tanah dan penyebaran kapur setelah 20 hari pembasahan.

\section{HASIL DAN PEMBAHASAN}

\section{Pengujian indeks properties}

Hasil indeks properties tanah asli dengan pengujian gradasi tanah tergolong jenis lempung, karena memiliki gradasi lempung sebesar 54,44\%. Hasil pengujian batas konsistensi tanah tergolong dalam $\mathrm{CH}$ dengan batas cair ( $L L)$ sebesar 114,05\%, batas plastis (PL) sebesar 42,29\%, nilai indeks plastisitas (PI) yang diperoleh sebesar $71,76 \%$ dan indeks susut (SI) sebesar 95,75\%, sehingga masuk dalam derajat pengembangan sangat tinggi.

Indeks properties setelah swelling 20 hari mengalami perubahan. Hasil uji batas konsistensi mengalami turun pada batas cair menjadi $74,26 \%$ dan batas plastis menjadi $41,72 \%$, sehingga dapat menurunkan hasil indeks plastisitas sebesar 47,17\%. Hasil klasifikasi menunjukkan perubahan dari $\mathrm{CH}$ ke $\mathrm{MH}$. Penurunan nilai batas cair diduga terjadi karena adanya pertukaran ion antara kapur dengan tanah yang mengakibatkan kemampuan penyerapan air menjadi berkurang.

\section{Perbandingan potensi mengembang (swelling)}

Pengamatan dibagi menjad 4 area untuk mempermudah dalam analisis dan pembahasan, pada Gambar 1 berikut :

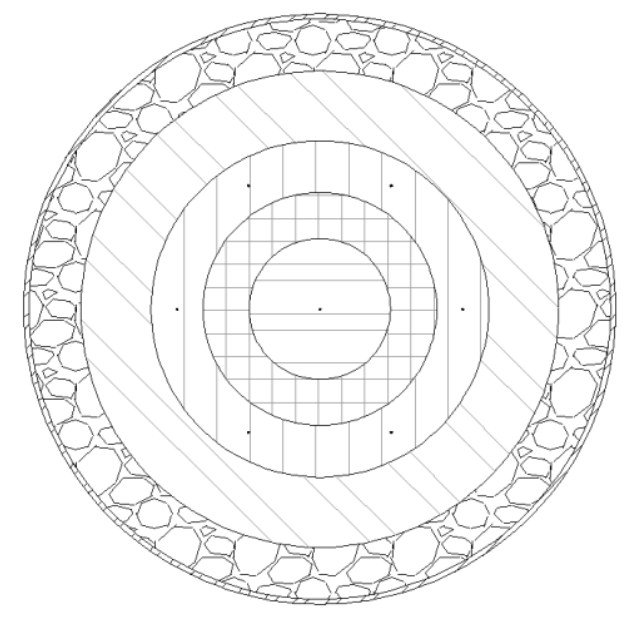

Tanpa kolom kapur

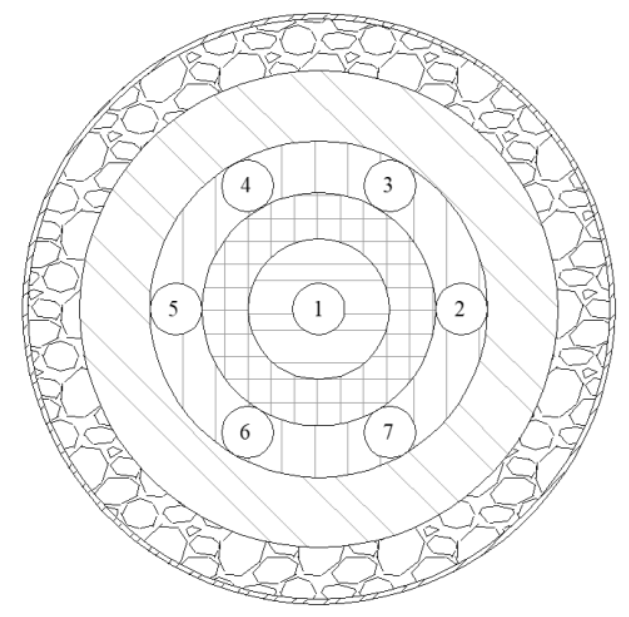

Dengan kolom kapur Keterangan :

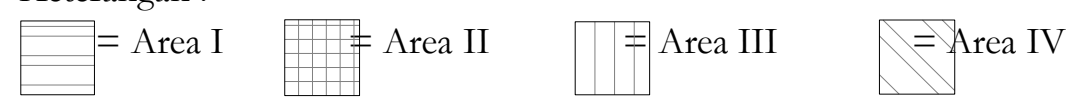

Gambar 1 Pembagian area pengamatan I, II, III, dan IV. 
Gambar 1 menunjukkan pembagian daerah pengamatan yang dibagi menjadi 4 area dengan penamaan area I, area II, area III, dan area IV. Pembagian area pengamatan ditentukan berdasarkan pertimbangan pengaruh kapur dengan jarak pengamatan dan pengaruh antara drainase di samping dengan kolom terluar. Hasil swelling selama 20 hari disajikan pada grafik berikut ini :

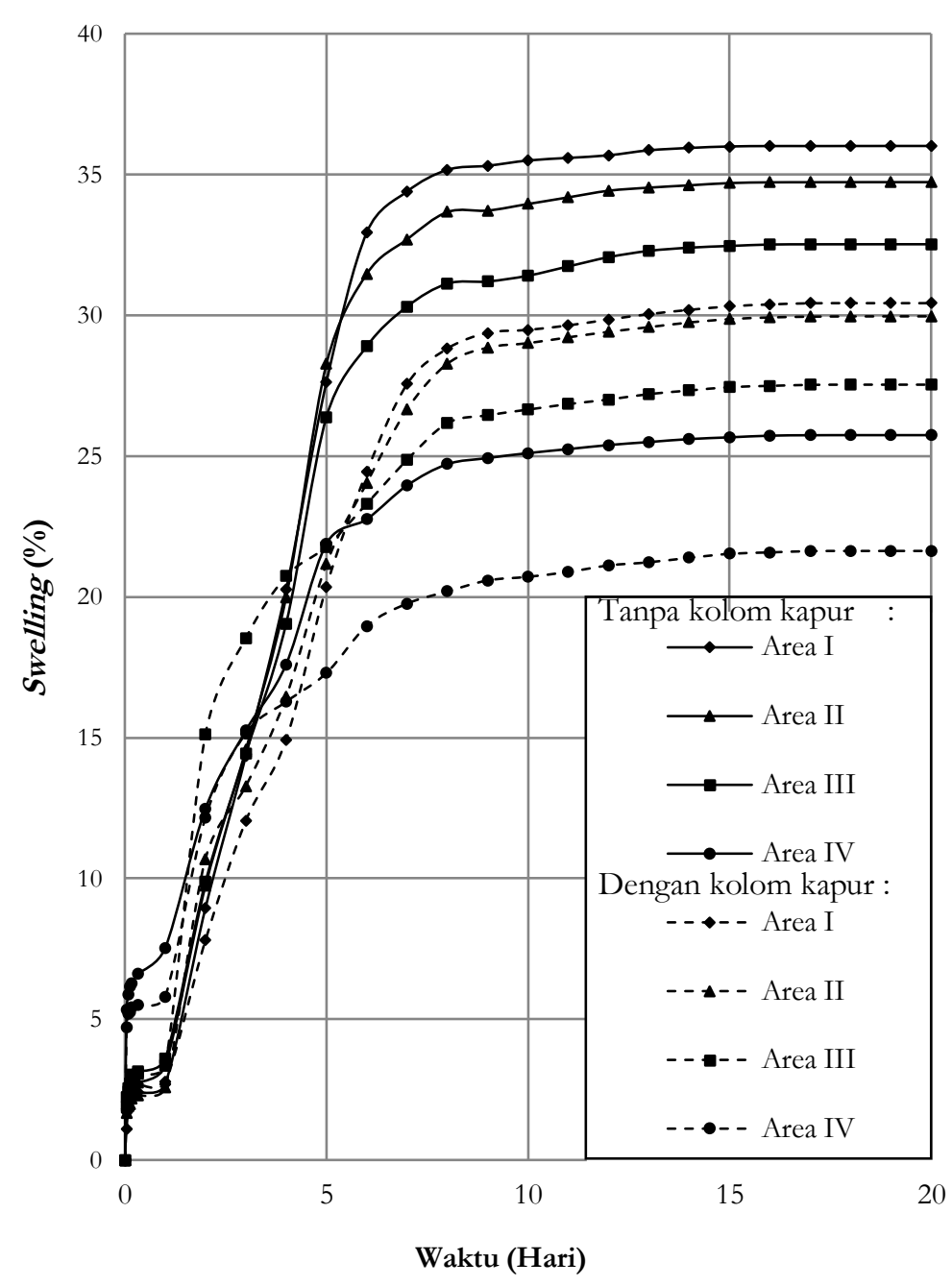

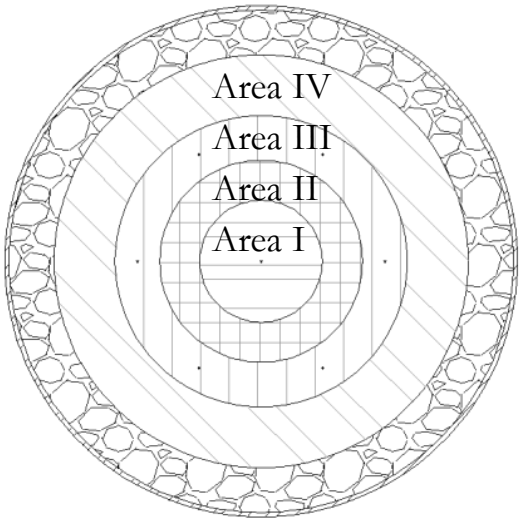

Tanpa kolom kapur

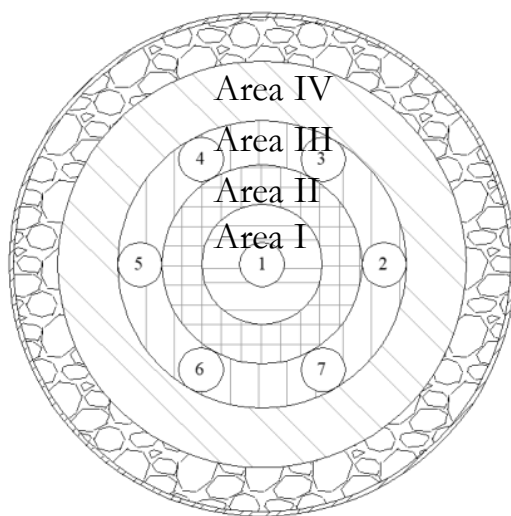

Dengan kolom kapur

Gambar 2 Swelling pada tanah pengamatan.

Gambar 2 memperlihatkan nilai potensi mengembang selama 20 hari pada tanah tanpa kolom kapur sebesar 31,90\% dan nilai potensi mengembang dengan kolom kapur sebesar 27,06\%, proses mengembang pada awal pembasahan mengalami peningkatan yang signifikan, dan akan mengalami asimtot pada hari ke 16. Perbedaan hasil swelling menunjukkan ada reduksi yang diduga terjadi karena kapur dapat berfungsi sebagai lubricant yang mengikat mineral tanah akibat pertukaran ion dan dapat menghambat proses mengembang.

Hasil reduksi disajikan pada Tabel 1 berikut :

Tabel 1. Reduksi swelling

\begin{tabular}{cc}
\hline Nama Area & Reduksi swelling (\%) \\
\hline Area I & 16,75 \\
\hline Area II & 15,02 \\
\hline Area III & 16,25 \\
\hline
\end{tabular}


Tabel 1 menunjukkan rata-rata reduksi swelling akibat pengaruh kolom kapur sebesar 15,02\% hingga $17,40 \%$.

\section{Perbandingan kondisi tanah selama 20 hari pengujian swelling}

Perbandingan kondisi tanah selama 20 hari pengujian swelling disajikan pada Gambar 3 berikut.
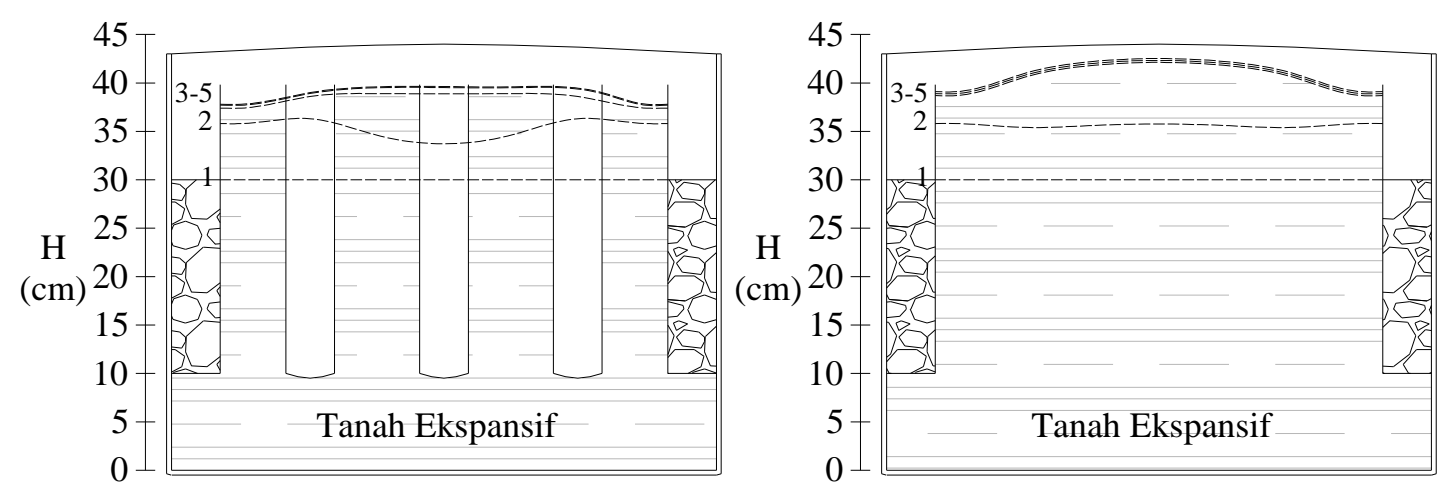

Gambar 3 Perbedaan tinggi selama 20 hari swelling.

Gambar 3 memperlihatkan perubahan ketinggian tanah selama swelling berlangsung. Tinggi tanah awal sebesar $30 \mathrm{~cm}$ dihitung dari dasar, pada hari ke 1 - 5 tanah cenderung mengembang lebih cepat di area IV, hal ini terjadi karena tanah di area IV lebih dekat dengan drainase sehingga tanah lebih singkat untuk terkena air. Hari ke 6 hingga akhir pengamatan memperlihatkan tanah di area I dan II mulai mengembang perlahan hingga pada akhir pengamatan terlihat menggunung. Pengaruh pemberian kolom kapur mulai terlihat pada hari ke 20, karena tanah tanpa kolom mengalami swelling sangat tinggi di area I, sedangkan pada tanah dengan kolom kapur swelling yang terjadi tidak lebih tinggi dari tanah tanpa kolom. Kondisi kolom pada model tes selama swelling 20 hari terlihat terangkat karena efek pergerakan vertikal tanah dan mengalami perubahan volume yang digunakan sebagai indikasi penyebaran kapur dalam tanah ekspansif.

\section{Perbandingan pengembangan volume}

Penyebaran kapur pada tanah dapat dibuktikan dengan adanya butiran kapur menempel di tanah sekitar kolom, tetapi kegiatan pembasahan yang dilakukan dengan interval waktu yang lama dapat melarutkan kapur hingga ke area yang labih jauh. Penggunaan casing dapat berfungsi sebagai indikator penyebaran kapur melalui perbahan volume yang terjadi.

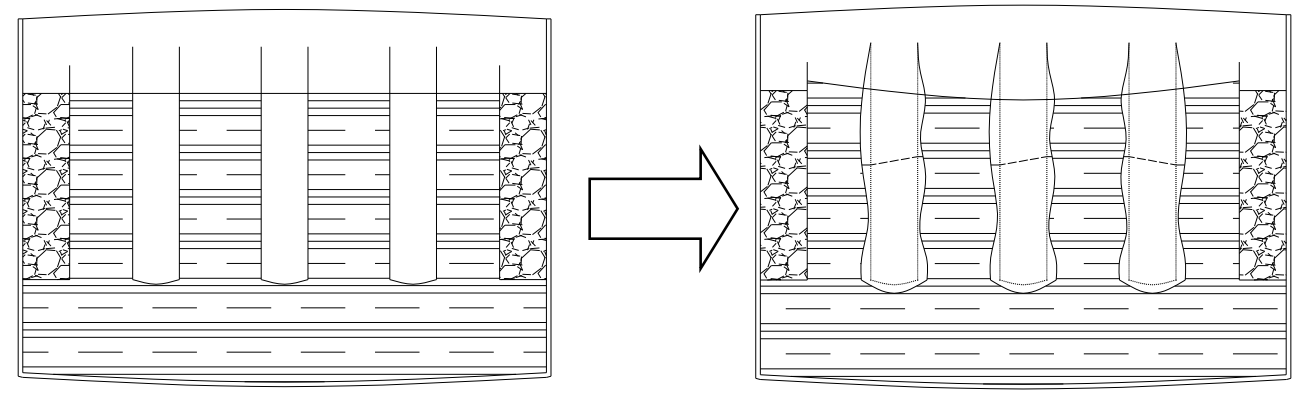

Gambar 4 Perubahan bentuk kolom kapur.

Gambar 4 menunjukkan adanya perubahan volume kolom kapur dengan rata-rata meningkat sebesar 18,33\%. Reaksi kapur dengan air menyebabkan kapur mengembang dan berubah menjadi butiran halus bila terganggu, sehingga dengan bantuan air ada kecenderungan kapur terkikis dan menyebar.

\section{Perbandingan hasil Unconfined Compression Strength (UCS)}

Perbandingan nilai UCS hasil pengujian disajikan pada Tabel 2 berikut :

Tabel 2 Perbandingan hasil uji UCS

\begin{tabular}{|c|c|c|c|}
\hline Pengujian & Satuan & Tanpa kolom & Dengan kolom kapur \\
\hline
\end{tabular}




\begin{tabular}{llccc}
\hline & & & Area I, II, III & Area IV \\
\hline $\mathrm{q}_{\mathrm{u}}$ & $\mathrm{kN} / \mathrm{m}^{2}$ & 13,96 & 15,43 & 14,01 \\
\hline $\mathrm{S}_{\mathrm{u}}=\mathrm{C}_{\mathrm{u}}$ & $\mathrm{kN} / \mathrm{m}^{2}$ & 6,98 & 7,72 & 7 \\
\hline
\end{tabular}

Tabel 2 menunjukkan hasil kuat tekan bebas $\left(q_{u}\right)$ terbesar berasal dari sampel area I, II, III yang berada didekat kolom kapur sebesar 15,43\%. Hasil kuat tekan bebas $\left(q_{u}\right)$ sample area IV, tidak mengalami kenaikan yang signifikan bila dibandingkan dengan sample dari tanah tanpa kolom, perbedaan yang terjadi hanya sebesar $0,36 \%$.

Kenaikan hasil kuat tekan bebas diduga karena zat yang terkandung pada kapur telah bercampur dengan tanah sehingga terjadi pertukaran kation, selanjutnya terjadi peristiwa sedimentasi, dimana kapur menjadi keras dan memiliki kemampuan untuk mengikat tanah.

\section{Perbandingan hasil uji X-Ray Fluorescence (XRF)}

Perbandingan nilai hasil pengujian disajikan pada Tabel 3 berikut :

Tabel 3 Perbandingan unsur kimia dari hasil uji XRF

\begin{tabular}{ccc}
\hline Unsur Kimia & $\begin{array}{c}\text { Sebelum swelling } \\
(\%)\end{array}$ & $\begin{array}{c}\text { Setelah 20 hari } \\
\text { swelling }(\%)\end{array}$ \\
\hline $\mathrm{O}$ & 39,28 & 37,88 \\
\hline $\mathrm{Si}$ & 15,81 & 13,46 \\
\hline $\mathrm{Fe}$ & 14,57 & 13,02 \\
\hline $\mathrm{Ca}$ & 7,56 & 16,62 \\
\hline $\mathrm{Al}$ & 5,12 & 4,73 \\
\hline $\mathrm{Mg}$ & 2,06 & 1,75 \\
\hline $\mathrm{Ti}$ & 1,05 & 0,96 \\
\hline Komposisi lain-lain & 14,55 & 11,58 \\
\hline
\end{tabular}

Tabel 3 menunjukkan unsur kimia Ca mengalami kenaikan dari 7,56\% menjadi 16,62\% dan unsur yang lain tidak mengalami kenaikan maupun penurunan yang signifikan. Pertambahan konsentrasi kalsium pada hasil uji XRF dapat diartikan kapur sebagai material pengisi kolom berhasil menyebar kedalam tanah, sehingga menguatkan dugaan bahwa kapur pada kolom telah berhasil menjadi lubricant yang memperbaiki sifat dasar yang dimiliki tanah ekspansif.

\section{KESIMPULAN}

Kesimpulan yang diperoleh dari hasil penelitian pengaruh kolom kapur pada tanah ekspansif dengan pengaliran dari tanah ke kolom adalah sebagai berikut :

1. Penambahan kolom kapur dapat menurunkan nilai potensi mengembang tanah ekspansif sebesar $4,84 \%$.

2. Penyebaran kapur dari kolom dapat mengurangi nilai indeks plastisitas (PI). Hasil pengujian indeks plastisitas tanah setelah pembasahan 20 hari menurun sebesar 39,21\%.

3. Penyebaran kapur dari kolom dapat meningkatkan nilai kuat tekan bebas dan kuat geser undrained tanah. Kenaikan hasil kuat tekan bebas $\left(q_{u}\right)$ terbesar berasal dari sampel uji area I, II, III sebesar 9,53\% dan kenaikan nilai kuat geser undrained $\left(S_{u}\right)$ sebesar $10,36 \%$ pada area yang sama.

4. Kapur sebagai material pengisi kolom berhasil menyebar kedalam tanah. Uji XRF menunjukkan unsur kimia Ca mengalami kenaikan sebesar 9,06\% dan terjadinya perubahan volume kolom sebesar $18,03 \%$.

\section{DAFTAR PUSTAKA}

Sumiyanto, dan Apriyono, A., 2012 Efektivitas Injeksi Larutan Kapur untuk Menurunkan Plastisitas Tanah Lempung sebagai Upaya Mengatasi Kerusakan Jalan Raya, Jurnal : Universitas Jendral Soedirman.

Sumantry, T., 2013, Aplikasi XRF untuk Identifikasi Lempung pada Kegiatan Penyimpanan Lestari Limbah Radioaktif, Jurnal: BATAN. 
Fardiansyah, A., H., 2014, Pengaruh Variasi Penambahan Kadar Air Terhadap Tekanan Pengembangan Tanah Ekspansif Arah Vertikal, Jurnal: Universitas Brawijaya Malang.

Hardiyatmo, H., C., 2014, Permasalahan dan Penanganan Tanah Ekspansif, Yogyakarta : Gajah Mada University Press.

Hardiyatmo, H., C., 2014, Mekanika Tanah 1, Yogyakarta : Gajah Mada University Press. 